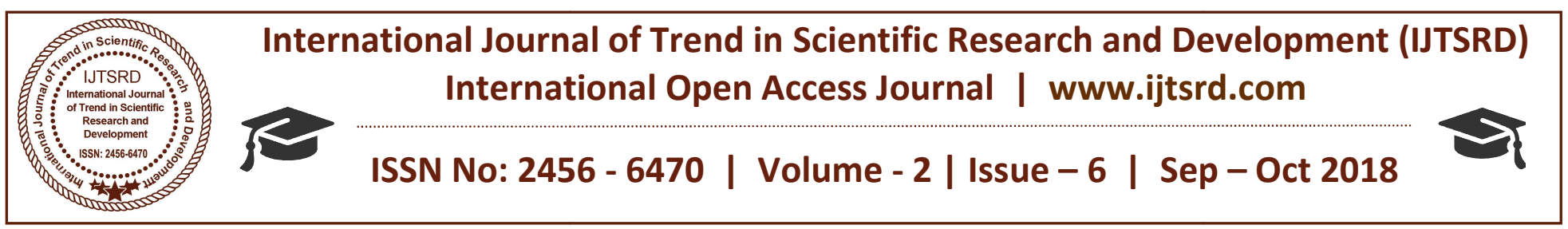

\title{
Parental Financial Commitment and its Effect on the Academic Achievement of Persons with Visual Impairment
}

\author{
Melem Linda Fangwi (PhD) \\ Department of Educational Psychology, Faculty of Education, \\ University of Buea
}

\begin{abstract}
Family financial resources, which are associated with parents' occupation and educational attainment, often imply increased learning opportunities both at home and in school and often result to a greater student's performance in school and their adjustment to life. This study examined the impact of parental financial commitment on the academic achievements of students with visual impairment in some selected residential schools in the North West region of Cameron. A sample of 50 pupils and 50 parents were purposively selected as participants in the study. Of this 50 pupils $44 \%(n=22)$ were males while $66 \%(n=$ 28) were females. A questionnaire was used to collect data from parents while a focus group discussion guide was used to collect data from the pupils. The principals of the two institutions were also interviewed using an interview guide. From the result obtained it was clear that parental financial commitments significantly influence the academic achievement of persons with visual impairment. It was therefore recommended that parents should identify resources available to the family and plan their finances to suit the needs of every family member knowing that the education of children with special needs entails a lot.
\end{abstract}

\section{Keywords: Parental Financial Commitment,} Academic Achievement and Persons with Visual Impairment

\section{INTRODUCTION}

Children are family members who bring challenges and responsibilities to their families that can be positive as well as negative. Members of a family influence each other, and the presence of a child with a disability in a family has an impact on the way the family functions. Families respond in many different ways to the arrival of a child with disabilities. As the first educators and cognitive stimulators of children, parents are the source of primary knowledge and cognitive orientation for children's start on life and school. As such they are expected to play a pivotal role of orienting and guiding their children toward the right ways of the family, the community and the world at large. Most importantly, although families differ in the way they adapt to the challenge of having a child with a disability, most families meet this challenge successfully, Adeyemo (2002).

\section{Background to the study}

Parenting a child with disabilities is an uphill task as there are many factors that may interplay with this. Every disability has its characteristics and behaviors that affect the family's functioning. Severe disabilities that are more visible may bring about excuses for inappropriate behavior or may lead to isolations from socialization (Pomerantz, Moorman, and Litwack (2007). Disabilities with uncertain outcomes may be emotionally stressful for families because parents may keep searching for appropriate treatment. Physical disabilities for example may affect not only the way a child feels about himself or herself, but also the attitudes of parents, brothers and sisters, and others in the community. Thus the nature of a disability is one factor that affects the ability to parent a child with disability.

Culture is part of all aspects of family life including how the child is raised, and beliefs about education, health care, and seeking support outside the family. Some cultures are more accepting of disability than others, and still other cultures view disabilities as a private matter or may even consider them shameful. Culture refers to beliefs, attitudes, and values of a 
family and may stem from ethnic background and/or religion. Culture also relates to geographical location, and different regions of the country may have different values. Family cultural affiliations affects the way families parent their children with disabilities (Jasen (2004).

Family structure such as single parent, two-parent, same-sex parent, and step parent families, as well as grandparents and unrelated live-in members has unique characteristic features that propels their responses to a child with disability. Family structure in this study does not only refers to its members, but also to how the family is organized. Chen, (2009) alleged that family characteristics are a major source of disparity in students' educational outcomes.

According to Blanden, Havemen, Smeeding and Wilson (2014), aside from the energy required to manage a child's physical and emotional needs, there are often huge financial considerations. A child's disability may require the family to retrofit their home, or obtain housing that is accessible. In addition, equipment, social services, and health care are often pricey and are not always covered by insurance or entitlement programs. Families that are able to get some or all of these expenses covered, often have to advocate for them on their own, and navigating disorganized government programs associated with these benefits can be an extremely taxing process in its own right. Usually a family spend more money on their child with disabilities than on their other children without disabilities. Expenses related to a child with a disability often result in financial hardship. Even with insurance, there is medical care, therapy, childcare, special equipment, transportation, laundry, and structural modifications for the home to accommodate a child or to repair damage, not to mention tutoring or summer programs or a special technological device for the child.

The physical and health needs of children with disabilities often require great effort, particularly when the disabilities are severe or the illnesses are chronic. Daily care includes bathing, dressing, toileting, and feeding as well as cooking, cleaning, washing. Going to the doctor, to the supermarket, or to a fast food restaurant can be a major undertaking. As children get older, it may become more difficult for parents to accomplish certain tasks such as dressing, moving the child in and out of the home, as well as moving them from place to place. Daily care over many years can lead to increased parental stress. Cindy (2017) beliefs that parents are responsible for ensuring that their children are well fed, well rested, happy and calm. Creating a positive physical and mental atmosphere in the home helps prepare students to ready and able to learn. A parent child relationship characterized by nurturing acceptance and encouragement as well as parents' responsiveness to the child's needs correlated with positive academic performance. Parental over protectiveness, authoritarianism, disapproval and punishment often have negative correlation with students learning. A student's learning success is enhanced when both teachers and parents clearly state their goals for the students' performance. Parents' positive aspirations for their children have a strong relationship with their academic performance. Parental expectations and communication about the value of learning and the child's skills have a powerful effect on the child's motivation to learn (Fan (2001).

Academic performance refers to the level of performance in school, accomplishment or success in school". However, academic performance is the core of educational growth (Aremu \& Oluwole, 2001). Jansen (2004) defined academic performance as the process of developing the capacities and potentials of the individual student so as to prepare that individual to be successful in a specific society or culture. From this perspective, education is serving primarily as an individual development function. It is important to keep in mind that academic performance may largely be a function of the context in which it takes place, and therefore the necessary abilities may also vary according to the context. In this regard it may be concluded that the concept, meaning and criteria of academic success may also vary according to the context in which it is found.

Tchombe, (2008) points out that, education is a crucial factor in social and personal development and an indispensable asset in the attempt to attain the ideals of peace, freedom and justice. Thus education is one of the principal means available to foster a deeper and more harmonious form of human development and thereby reduce poverty and exclusion. Exclusionary processes, which disadvantaged groups, continue to experience requires that appropriate mechanisms be placed to respond to the emerging issues. And one of such mechanism is the definition of parental role in the education of their children with visual impairment this is because they 
constitute a greater majority of those suffering from rejection and abandonment.

Steel (1991) indicates that the successful education of children with special needs is dependent on the full involvement of their parents. Parental involvement would seem to suggest that parents are the key educators of their children but this is not the case as parents are partners with various institutions in educating their children. It has been realized that an intensive educational input by parents in every aspect both at home and in school has a tendency to accelerate their children's performance.

According to Ihenacho, Hassana and Abdulahi (2008) parental involvement is important because it has been assumed to be a significant factor in defining the life and behaviour of persons with visual impairment. They reiterate that parental support is capable of enabling the visual impaired child to fully develop his or her potentials so as to be of help to self and the society at large.

More family financial resources, which are associated with parents' occupation and educational attainment, often imply increased learning opportunities both at home and in school. Better educated parents can contribute to their children's learning through their day to-day interactions with their children and involving themselves in their children's school work. Parents with higher occupational status and educational attainment may also have higher aspirations and expectations for their children's occupation and education, which in turn can influence their commitment to learning (Ushie, Onongha, Owolabi, and Emeka, 2012).

According to Caro (2009), socio-economic status (SES) of parents is an important explanatory factor that influences students' overall performance in school, as students who have low SES earn lower test scores and are more likely to drop out of school. Low SES negatively affects academic performance because it prevents access to vital resources and creates additional stress at home. Similarly, parent's level of education has a proven influence on students' academic achievement. Educated parents are more likely to use complex language and a wider vocabulary with their young children (Penny, 2001). Parents with lower levels of education are less likely to get involved in the school. Better-educated parents are familiar with how schools work and are likely comfortable with school structure.

Cindy (2017) holds that, the home environment provides the foundation for learning and is an element of the student's life that affects his or her grades. She believes that success in education for children is positively impacted by the home such as parents reading to their children, trips to the library, and provision of resources encouraging play with letters and numbers.

Blanden, Havemen, Smeeding and Wilson (2014) holds that visual impairment is decreased ability to see that causes problems not fixable by usual means such as glasses. As of 2015 there were 940 million people with some degree of vision loss, 246 million had low vision and 39 million were blind (WHO statistics 2018). The main causes of visual impairments include: Onchocerciasis (0.7\%), Trachoma (3\%), Childhood blindness (3\%), Diabetic retinopathy (4\%) ARMD (7\%), Glaucoma (10\%), Uncorrected refractive errors (18\%), Cataract (39\%), Other (11\%).

\section{Major risk factors for visual impairment due to} eye diseases

Age: Visual impairment is unequally distributed across age groups, as more than $82 \%$ of all blind people are 50 years of age or older, even though people in this age group represent only $19 \%$ of the world's population. The prevalence of blindness among children is about 10 times lower than that among adults, childhood blindness remains a high priority because of the expected number of years to be lived with blindness. About one-half of the estimated 1.4 million cases of blindness in children below the age of 15 could have been avoided Penny (2001).

Gender: Studies consistently indicate that females in every region of the world and of all ages have a significantly higher risk for being visually impaired than males, mostly because of their longer life expectancy and, in poorer societies, because of their lack of access to services (WHO statistics 2018).

Socioeconomic status: More than $90 \%$ of the world's visually impaired people live in developing countries. Other risk factors include tobacco use, exposure to ultraviolet radiation, vitamin A deficiency, high body mass index and metabolic disorders. WHO has estimated that up to three-quarters of all blindness worldwide is avoidable. In children, about one-half of the causes can be prevented or treated. 
In most cultures in Cameroon, children with visual impairments are believed to have come from the world of evil spirits and bear curses which render them unable to contribute positively to the development of the community. In some villages blindness was considered as an offence against the gods and a curse. Consequently, there was no regard for such persons or their families in the community. All of these were due to ignorance and prejudice. It is worth noting however that this study was carried out in 2006 and today the mind set of most people in these regions have changed and as such their attitude towards the visually impaired have changed over time (Yuh and Shey 2008).

Very few specialized institutions exist to cater for the education and rehabilitation of persons with visual impairment in Cameroon. In the North West and South West Regions of Cameroon we have; the Rehabilitation Institute for the Blind in Buea, the Cameroon Baptist Integrated School for the Blind at Kumbo and the Saint Joseph's Children and Adult Home at Mambuh Bafut which is a centre for multiple disabilities (with the visually impaired inclusive). These institutions play a significant role in the education and rehabilitation of persons with visual impairment most especially those who are completely blind. The is a law in Cameroon which addresses the needs of persons with disabilities Law No 83/013 of July 1983 relating to the protection of persons with disabilities. Though these laws address the education of persons with visual impairment, there is however no law or plan of action towards the inclusion of the family in the education of persons with visual impairment as well as persons with disabilities in general. No multi -disciplinary team actually exist to aid these children in their different area of disabilities.

According to the Taxas School for the blind and the visually impaired (2018), socioeconomic status is a great factor in parental involvement in the education of their children with visual impairment. If there are few resources to deal with the basic needs of food, shelter, clothing, and medical care the ability of parents to manage their emotional reaction will be stretched to the breaking point.

It is important to the visually impaired child that he or she feels accepted within the family being treated like other kids can help build this feeling of security. The child's self-esteem is closely related to how he or she perceives his or her value within the family. Nurturing parents regardless of socioeconomic status are good for every child but crucial for the visually impaired. Pride in child's achievement no matter how small and praise for effort can build a sense of accomplishment.

Visual impairment can interfere with the bonding process (the child may not make eye contact, may startle when touched, or may turn head away) thus parents need extra support and counseling to resolve miscommunication issues and resolve thus the Critical and Social Constructionist Theory of Disability by Oliver (1998) fits squarely in this study.

Coleman (2000) defines financial commitment as parental ability to invest their financial capital in the academic life of their children irrespective of their nature. He states that investing in children and promoting their successful development is intertwined with the concepts of social, financial and human capital which are central resources from the family that are believed to be necessary for a child's successful development and are resources which will be valuable for the child's success in the future. He further states that children whose parents invest these capitals in their education holds a positive attitude towards school and are well adjusted emotionally and socially.

For the visually impaired child to actually advanced in his or her education the following according to Okantey, (2008) are necessities and must be provided for by parents or sponsors of these children. The ability to provide these things is not only based on the parent's financial capabilities but also on their educational level: braille papers, Stylus, Abacus dice, Cuberisme, Support board, Speech synthesizers, Screen reader. Warnock (1978) holds that parental collaboration with schools will facilitate the purchase of these items that will enable the visually impaired child to develop academically. However, Adeyemo (2002) believes that poverty is one of the most crucial issues affecting the education of the visually impaired in Africa. Parents may have the interest to sponsor their visually impaired children but financially they are handicapped by poverty. Thus one of the major barriers to the education of the visually impaired in Africa is poverty.

Blanden,Wilson, Smeeding and Haveman (2014) said that, parental education and occupational class are more strongly associated with student's educational attainment. It has been put forward that parents of high socio-economic status have more positive 
attitudes towards their children's schooling and have high expectations for the children since they have the economic empowerment to buy the advantages that money can buy. Money may encourage or discourage going to school. The children from comfortable homes eat balanced diets and thus have a good health. Again, the values he/she is exposed to at home are similar to the ones he finds in school and therefore he is able to adjust easily to school life. A feeling of belonging to a comfortable social environment further helps him/her to show his best. Payne, (1998) believes that students from poverty stricken families lack cognitive strategies needed to be successful in the educational system. Conger and Elder (1994) asserts that families at a variety of income levels who suffer economic stress of any kind are more likely than families that are not economically stressed to experience depression, marital clashes and to be harsh with their children which points to the fact that, poverty and economic stress are associated with parent- child conflict which leads to poorer grades and weakens emotional and social growth. The disparity in home learning environment of higher and lower income children is a reason for nearly half of the effect income on the achievement scores of preschool children (Klebanor, 2002).

The academic performance of any child cannot be separated from the home environment in which the child grows up. Numerous studies revealed that various factors are responsible for scholastic failure of students, such as low socio-economic background, student's cognitive abilities, school related factors, environment of the home, or the support given by the parents and other family members (Khan \& Malik, 1999; Fan, 2001; Gonzalez-Pienda et al., 2002). Parental socioe-conomic characteristics to a greater extent determine student's performance in school and their adjustment to life (Aikens et al., 2008). Family financial resources, which are associated with parents 'occupation and educational attainment, often imply increased learning opportunities both at home and in school. Indeed, family background is the foundation for children's development, as such family background in terms of family type, size, socioeconomic status and educational background play important role in children's educational attainment and social integration (Ushie et al., 2012). The home has a great influence on the child's psychological, emotional, social and economic state.

\section{Statement of the Problem}

Despite all the international mechanisms to protect and encourage the education of persons with special needs, many obstacles still exist that obstruct such access. In our community there is more rejection and abandonment of persons with visual impairment at institutions by their parents. This is the case at the Saint Joseph's children and adult home Bafut and at the C.B.C Integrated School for the Blind in Kumbo. Parents pay little attention to the psychological, educational, social and financial needs of these children. They shift their parental role and responsibilities to the institutions. This attitude of rejection stems from the socio- The actual problem is that parents have shifted their responsibilities to the institutions, they do not make provision for the basic needs of these children such as books, pen, pencils and even tuition keeping aside the children's personal needs. Parents are failing in their responsibilities to support these children's education in the domain of material and financial provision as well as psychological support. Parental non involvement in the academic lives of persons with visual impairment hampers the academic performance of these children.

\section{Research objective}

To find out how parental financial commitment affects the academic live of persons with visual impairment.

Research question: how does parental financial commitment affect the academic lives of persons with visual impairment?

Research hypothesis: Null: Parental financial commitments do not significantly influence the academic performance of persons with visual impairment.

Alternative: Parental financial commitments significantly influence the academic performance of persons with visual impairment.

\section{Research methodology}

The population of the study consisted of all pupils with visual impairment and their parents in residential schools in the North west region of Cameroon. A sample of 50 pupils and 50 parents were purposively selected as participants in the study. Of this 50 pupils $44 \%(n=22)$ were males while $66 \%(n=28)$ were females. A questionnaire was used to collect data from parents while a focus group discussion guide was used to collect data from the children. The 
International Journal of Trend in Scientific Research and Development (IJTSRD) ISSN: 2456-6470

principals of the two institutions were also the survey research design was used in carrying out interviewed using an interview guide. Data was the study.

analysed using descriptive and inferential statistic and

FINDINGS AND DISCUSSIONS

Table showing the Relationship between Parental Regular Financial Commitment and the Academic Performance of Persons with Visual Impairment

\begin{tabular}{|c|c|c|c|c|c|c|c|c|c|}
\hline \multirow{2}{*}{$\begin{array}{l}\text { Parental financial } \\
\text { commitment }\end{array}$} & \multicolumn{2}{|r|}{ Good } & \multicolumn{2}{|c|}{ Average } & \multicolumn{2}{|c|}{ Poor } & \multicolumn{2}{|c|}{ Total } & \multirow{2}{*}{$\begin{array}{l}X^{2} \text {-Test } \\
(\mathbf{P} \\
\text { Value })^{*}\end{array}$} \\
\hline & Agree & Disagree & Agree & Disagree & Agree & $\begin{array}{l}\text { Disagre } \\
\text { e }\end{array}$ & Agree & Disagree & \\
\hline $\begin{array}{l}\text { I regularly pay my } \\
\text { child's } \\
\text { requirement in school }\end{array}$ & $\begin{array}{l}9 \\
(64.3 \%)\end{array}$ & $\begin{array}{l}5 \\
(45.7 \%)\end{array}$ & $\begin{array}{l}12 \\
(100 \%)\end{array}$ & $\begin{array}{l}0 \\
(0.0 \%)\end{array}$ & $\begin{array}{l}8 \\
(88.9 \%)\end{array}$ & $\begin{array}{l}1 \\
(11.1 \%)\end{array}$ & $\begin{array}{l}29 \\
(82.9 \%)\end{array}$ & $\begin{array}{l}6 \\
(17.1 \%\end{array}$ & $\mathrm{P}=0.047$ \\
\hline $\begin{array}{l}\text { I provide all for my child } \\
\text { to be well taken care of } \\
\text { medically. }\end{array}$ & $\begin{array}{l}11 \\
(78.6 \%)\end{array}$ & $\begin{array}{l}3 \\
(21.4 \%)\end{array}$ & $\begin{array}{l}12 \\
(100 \%)\end{array}$ & $\begin{array}{l}0 \\
(0.0 \%)\end{array}$ & $\begin{array}{l}7 \\
(77.8 \%)\end{array}$ & $\begin{array}{l}2 \\
(22.2 \%)\end{array}$ & $\begin{array}{l}30 \\
(85.7 \%)\end{array}$ & $\begin{array}{l}5 \\
(14.3 \%)\end{array}$ & $\mathrm{P}=0.218$ \\
\hline $\begin{array}{l}\text { I regularly provide } \\
\text { proper care and } \\
\text { nourishment to my child } \\
\text { in school. }\end{array}$ & $\begin{array}{l}9 \\
(64.3 \%)\end{array}$ & $\begin{array}{l}5 \\
(35.7\end{array}$ & $\begin{array}{l}11 \\
(91.7 \%)\end{array}$ & $\begin{array}{l}1 \\
(8.3 \%)\end{array}$ & $\begin{array}{l}7 \\
(77.8 \%)\end{array}$ & $\begin{array}{l}2 \\
(22.2 \%)\end{array}$ & $\begin{array}{l}27 \\
(77.1 \%)\end{array}$ & $\begin{array}{l}8 \\
(22.9 \%)\end{array}$ & $\mathrm{P}=0.253$ \\
\hline $\begin{array}{lr}\text { I always } & \text { provide my } \\
\text { child's } & \text { educational } \\
\text { needs. } & \end{array}$ & $\begin{array}{l}10 \\
(71.4 \%)\end{array}$ & $(28.6 \%)$ & $\begin{array}{l}11 \\
(91.7 \%)\end{array}$ & $\begin{array}{l}1 \\
(8.3 \%)\end{array}$ & $\begin{array}{l}7 \\
(77.8 \%)\end{array}$ & $(22.2 \%)$ & $\begin{array}{l}28 \\
(80.0 \%)\end{array}$ & $\begin{array}{l}7 \\
(20.0 \%)\end{array}$ & $\mathrm{P}=0.429$ \\
\hline $\begin{array}{l}\text { My regularly financial } \\
\text { commitment affects my } \\
\text { child's academic and } \\
\text { social life positively. }\end{array}$ & $\begin{array}{l}12 \\
(85.7 \%)\end{array}$ & $(14.3 \%)$ & $\begin{array}{l}12 \\
(100 \%) \\
\text { ernat }\end{array}$ & $\begin{array}{l}0 \\
(0.0 \%) \\
0 \text { hal }\end{array}$ & $\begin{array}{l}8 \\
(88.9 \%) \\
0.4 \%\end{array}$ & $\begin{array}{l}1 \\
(11.1 \%) \\
9\end{array}$ & $\begin{array}{l}32 \\
(91.4 \%)\end{array}$ & $\begin{array}{l}3 \\
(8.6 \%)\end{array}$ & $\mathrm{P}=0.410$ \\
\hline Aggregate score (MRS) & $\begin{array}{l}51 \\
(72.9 \%)\end{array}$ & $\begin{array}{l}19 \\
(27.1 \%)\end{array}$ & $\begin{array}{l}58 \text { en } \\
(96.7 \%)\end{array}$ & $\begin{array}{l}2171 \\
(3.3 \%)\end{array}$ & $\begin{array}{l}37 \text { TTh } \\
(82.2 \%)\end{array}$ & $\begin{array}{l}8 \\
(17.8 \%)\end{array}$ & $\begin{array}{l}146 \\
(83.4 \%)\end{array}$ & $\begin{array}{l}29 \\
(16.6 \%)\end{array}$ & $\mathrm{P}=0.001$ \\
\hline
\end{tabular}

Chi square critical value $\left(\mathrm{X}^{2}\right)=13.35$

Degree of freedom $(\mathrm{df})=2$

$\mathrm{P}$ value $=0.001$

From the table above, we realized that, there was statistically a significant relationship between parental financial commitment and visually impaired children's academic performance ( $\chi 2$-test; $\mathrm{P}=0.001)$. Students of parents with more financial commitment performed better than those with less financial commitment with percentage of $96.7 \%$. While those with less financial commitment performed poorly with percentage $82.2 \%$.
Table Parents view with respect to the effect of their financial commitment on the visually impaired student's academic life

\begin{tabular}{|c|c|c|c|}
\hline \multirow[t]{2}{*}{ Component } & \multirow[t]{2}{*}{ Indicators } & \multicolumn{2}{|c|}{ Percent of Cases } \\
\hline & & $\mathrm{N}$ & $\%$ \\
\hline \multirow{5}{*}{\multicolumn{2}{|c|}{$\begin{array}{l}\text { Effects of parental Motivation to learn } \\
\text { regular financial Regular in class } \\
\text { commitment on Psychological } \\
\text { child's academic stability } \\
\text { nerformance }\end{array}$}} & 16 & $35.6 \%$ \\
\hline & & 31 & $68.9 \%$ \\
\hline & & 35 & $77.8 \%$ \\
\hline & & & \\
\hline & & 16 & $35.6 \%$ \\
\hline & Foster self esteem & 5 & $11.1 \%$ \\
\hline & Foster fluency & 1 & $2.2 \%$ \\
\hline Total & & 50 & $100.0 \%$ \\
\hline
\end{tabular}

This table presents to us the effects of parental financial commitment to the academic achievement of persons with visual impairment. From the table therefore we deduced that $35(77.8 \%)$ of parents believed that their financial commitment enables their children to be regular in class, $31(68.9 \%)$ of them 
believe that it motivates them to learn. $16(35.6 \%)$ of the parents holds that it makes them accepted by all, 16 (35.6\%), also holds that it makes them psychologically stable and lastly $5(11.1 \%)$ believed that it fostered fluency in the children. From this finding it is obvious that parental financial commitment towards the education of their children with visual impairment significantly influence their academic performance.

It was clear from the analysis of qualitative and quantitative data that; parental financial commitment influences the academic achievement of the visually impaired. What is important to be noted here is the fact that parental financial commitment does not only mean the payment of fee but also the provision of material, medical, educational and physiological needs of the children. Parental financial commitments engulf parental school visitation, interaction and even motivation. Parental ability to visit their children is determined by the financial capability of these parents as well as the ability to buy gifts for these children thus one can say that parental financial commitment is a great determinant of the academic outcome of persons with visual impairment, because with it all the other indicators of parental school based involvement can be met such as parental motivation, interaction and school visitation. Parental financial commitment is beneficial to their visually impaired children in diverse ways it enables them to stay in class, it gives them a sense of acceptance, it motivates them to learn, foster their self-esteem, foster fluency, and psychological stability. These according to Pomerantz et al (2007) are qualities that instill in children positive attitude to study and with such, success is bound to come.

From the qualitative data obtained from the principals, we realised that most parents have serious problem meeting their financial obligations "In terms of payment of the P.T.A dues we are still having serious problems with most parents though the school has decided that this money could be paid in terms of food stuff yet some parents are still adamant to pay."

The children themselves stated that they were not very satisfied with their parents' level of financial commitment "In terms of provision of needs they are really trying but there are some basic requirements they can afford but they are not willing to buy. Things like brail machines are too expensive for them but at least they can afford tape recorders but in the entire school there is just one student with a tape recorder".
According to the children when their financial obligations are not met they become timid and shy. Shyness according Zimbardo (1992) is a great disadvantage for preteens and teens irrespective of their nature. Most societies favor bold and expressive children, while shy children are perceived negatively. Those who share the stress of shyness find it difficult to change. Many times they feel like cripples wondering what feeds the aloofness. A shy teen will not raise his hand in class to read his homework even if he has done an impeccable job. In open discussions, he would rather be quiet. A shy teen will rarely disclose his opinions and beliefs.

They rarely initiate discussions, make invitations or make social calls. Their favorite activity is spending most of their time in their private room, where everything is familiar and secure. When a teacher turns to them and invites them to participate in public discussions, they speak in a low voice and will barely be heard. Zimbardo (1992) reiterates that, initiating a simple dialogue with someone they like in class seems laborious, strenuous and sometimes even grotesque.

The inability to provide the needs of the visually impaired has been attributed to "poverty and ignorance". According to sacker et al (2002) the poorer people's circumstances the more difficult it is assumed to be, of support to a child's educational development. Thus they further state that, inequality in educational achievement and adjustment comes about as a result of the inequality in the financial capabilities of parents. Okantey (2008) believes that Parental educational level which leads to good income empowers parents to give their children a solid foundation for school and life success and enables them to build up strong partnerships between parents and schools in order to sustain achievement standards. It also heightens parents' feelings of competence and confidence in guiding their children's education. I wish to join Stoddard, Valcante, Roemer and O Shea (1994) and Dyson (1996) in a study documented in Turnbull (1999) to say that parental financial commitment is the most significant determinant of the academic outcomes of persons with visual impairment in the North West region of Cameroon.

Conclusion: From the findings it is apparent that parental financial commitment impacts the children with a sense of belonging, makes them regular in class, gives psychological stability, foster their selfesteem, give them a sense of self-worth, foster fluency, makes them feel loved, and accepted. The 
findings also show that parental financial commitment increases the academic achievement of persons with visual impairment.

\section{Recommendations}

$>$ Identify organizations that provide support services. Use the Internet to find support groups and services (vocational rehabilitation services).

$>$ Seek legal advice about special needs trusts designed for families of children with disabilities when children are young.

$>$ Identify resources available to the family.

$>$ Arrange for financial planning. Get information about financial benefits the family is entitled to receive (Social Security).

\section{References}

1) Aremu, O. A. \& Oluwole, D.A. (2001). Gender and birth order as predictors of normal pupils' anxiety pattern in examination. Ibadan Journal of educational studies 1(1) 1-7

2) Caro, D. H. (2009). Socio-economic status and academic achievement trajectories from childhood to adolescence. Canadian Journal of Education, 32, 558-590.

3) Chen, J.J.L. (2009) Relation of parental, teacher and peer support to academic engagement and achievement among Hong Kong students. School psychology international 29, 183-198

4) Cindy Hills (2017), what are the effects of the home environment on learning. Short term memory development; lives strong.com tracker.

5) E, Pomerantz, E. A. Moorman, \& S. D. Litwack, (2007). The How, Whom and Why of Parents Involvement in Children's Academic Lives More is not Always Better. Review of Educational Research, 77, 373 - 410

6) Euhprasia Yuh and Patrick Shey. (2008); The Education of Persons with Special Needs in Cameroon. A Historical Perspective. African Journal of Special Education (AJOSE) vol 1 No 1 pp 27-32

7) Fan, X (2001). Parental Involvement and students' academic achievement: a growth modeling analysis. Journal of Experimental Education 70, 27-61

8) G. O., Adeyemo. (2002). Excelling in life. An examination Guide published by Feyisetan press, Ibadan, Nigeria ISBN 978 2508-94-3
9) Gonzalez-Pienda, J.A. Nunez, J.C. Gonzalezpumariega, S., Alvarez, L., Roces, C. \& Garcia, M. (2002). A structural equation model of parental involvement motivational and aptitudinal characteristics and academic achievement. Journal of Experimental Education, 70., 257-287

10) Izuka J Ihenacho, Hassana $S$ Darma, Ali $T$ Abdulahi (2008); Classification of Special Needs Teaching Strategies and Rehabilitation. African Journal of Special Education (AJOSE) vol $1 N o$ Ipp 59-71

11) Jansen, J. D. (2004). Race and education aften ten years. Perspective in Education 22 (4): 117-128

12) J. O. Blanden, Robert Haveman, Timothy Smeeding, and Kathryn Wilson,(2014). Intergenerational mobility in the United States and Great Britain: a comparative study of parent-child pathways. http://eprints.ise.ac.uk/59332/

13) Khan \& Malik, (1999) Effectiveness of Parent's Involvement in Reading, Child's Overt Behavior at Home, Mother's Educational Level on Children's Reading Comprehension. Journal of Elementary Education 21, 68-91.

14) Nsamenang A.B (2004); Teaching Learning Transaction. An Afri centric Approach to Educational psychology. HDRC publications Bamenda.

15) Okantey, (2008). The Effect Of Parental Education Attainment on School Outcome Psychologia Science Parents Programme, Benin Bailoz publication

16) Oliver (1998) A social Constructionist Approach to disability: implications for special education. Exceptional child, 77367-384.

17) Penny, M. (2001). Understanding children's challenging behavior why try to influence or change behavior for a variety of purposes: Richmond Nelson.

18) Therese Mungah Shalo Tchombe. (2008); Understanding and Teaching Children with Special Needs in Ordinary Schools- Independence is priceless, we make it. African Journal of Special Education (AJOSE) Vol 1No1 pp iv-vii

19) Ushie, M. A., Onongha, G. L., Owolabi, E.O., \& Emeka, J.O., (2012) influence of family structure on students' academic performance in Agegelocal government area, Lagos State, Nigeria. European Journal of Education Studies 4, 177- 187.

20) Zimbardo, (1992). Psychology and Life $13^{\text {th }}$ ed New York Harper Collins. 